\title{
Visualising molecules: on-line simulations and virtual reality
}

\author{
J. Trindade, J. C. Paiva and C. Fiolhais \\ Center for Computational Physics, Physics Department, \\ University of Coimbra, 3000-516 Coimbra, Portugal
}

Science education, in particular physics Seducation, is being changed by the use of new technology. One of the most promising means of teaching and learning science is the Internet. A lot of material has appeared on the Web. Its impact in education has in most cases still to be evaluated.

Relatively small and less developed countries like Portugal offer interesting ground for observing the dissemination of computers in science education. The Portuguese Physical, Chemical and Mathematical Societies set up, in 1991, a common action - "Softsciences - for creating, producing and distributing software for learning Science and Mathematics, especially at the middle and high schools levels. "Softsciences" had the intention of making somewhat "softer" the learning of the socalled "hard" sciences, but without compromising rigour. The Ministry for Education and the Ministry for Science and Technology have supported this project.

In 1997 all software programs were brought together in a CD-ROM, under the suggestive title "Omniscience". A multimedia program was included ("Multimedia Periodic Table") as well as copies of Web pages with abundant teaching and

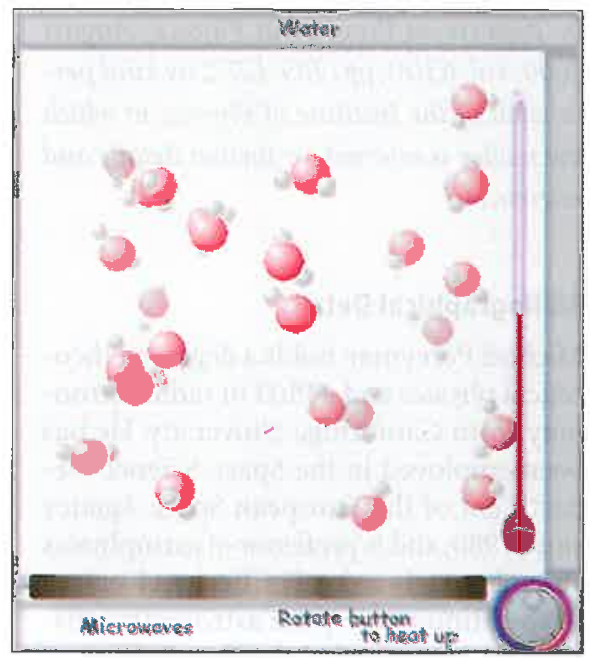

Fig, 1: Water molecules inside a microwave oven. This picture was created in "Java". Translations, rotations and vibrations take place at the same time. learning resources. A copy of the CDROM was given to all (around 1500) Portuguese middle and high schools. "Omniscience" has a home page with the address: http://nautilus.fis.uc.pt/ softc/omni98, through which new materials have been offered (in Portuguese).

Our work in the group "Computers in Science Education" at the Centre for Computational Physics of the University of Coimbra, which gained experience with "Omniscience", is now centred on on-line materials. The Web gives much more accessibility and universality compared with offline programs (see, for example, Web Multimedia Periodic Table in http://nautilus. fis.uc.pt/st2.5/). On-line simulations in "Java" are a convenient format for representing many physical phenomena in a pedagogic way. They may be used interactively, without the need for downloading and installing.

Another method for visualizing and manipulating scientific concepts goes under the name of virtual reality, a technique where virtual scenarios are felt as real by users. This novel technique, which is becoming cheaper, needs further testing and evaluation.

We describe here two recent experiments which are being carried out by us and which use on-line simulations and virtual reality in the teaching and learning of the structure of matter.

\section{"Molecularium": On-line simulations in Physics and Chemistry}

In the project "Molecularium" we aim to produce a set of computational simulations for the Internet dealing with various physical-chemical processes (http:// nautilus.fis.uc.pt/molecularium). Based on recent Internet technologies, our aim is the teaching and the learning about the microscopic world. One of the main problems in science education is experienced by students when faced with abstractions. Computer visualization tools are particularly effective to overcome this problem. For example, when learning the atomic and molecular structure of matter, the progressive familiarization with scientific models benefits from static and dynamic representations of the building blocks of matter.

The simulations that we are building relate to thermodynamical concepts (pressure and temperature), phases (solids, liquids and gases) and phase transitions, energy and entropy, and some assorted chemical phenomena (chemical equilibrium, salt dissolution, etc.). Our target groups are final year high school students and university freshmen.

One simple example of the "Molecularium" aims to help students to understand how food (containing water) is heated in a microwave oven (http://nautilus.fis.uc.pt/ molecularium $/ \mathrm{mw}$ ). Rotating a button, radiation is transferred to the molecules (Fig. 1) which start to undergo faster rotation. Their vibrational and translational motion is also increased and the thermometer rises, indicating an increase in temperature. Of course, one of the drawbacks of this simulation is the lack of quantal features, such as the quantum nature of molecular rotation.

Another example is the solid-vapor transition in iodine (http://nautilus.fis. uc.pt/molecularium/sv). It helps students to understand the influence of the division of the solid phase in the microscopic rate of the transition (Fig. 2). They could graph why iodine sublimation gets faster when the substance is pulverized.

\section{"Virtual Water": Virtual reality for understanding of water}

Some of the animations in the "Molecularium" are in 3D (Fig 1). Virtual reality (KALAWSAKY, 1993) extends the traditional 3D graphics world to include stereoscopic, acoustic, haptic (i.e., related to touch) and other feedbacks to create an al-

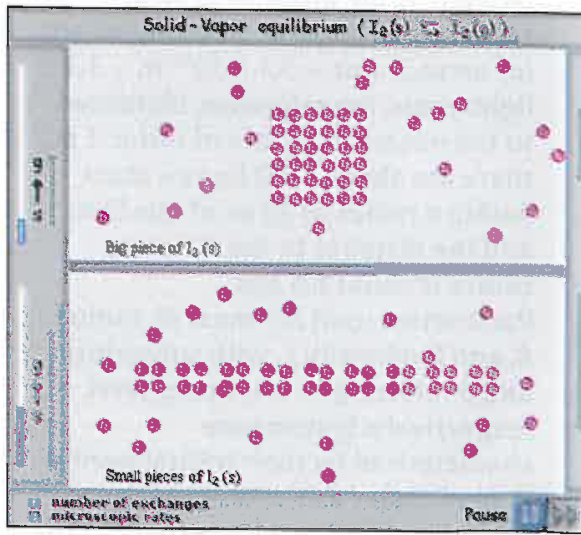

Fig. 2: Solid-vapor equilibrium for different divisions of the solid. For simplicity, the iod molecules are represented as single sphere which are vibrating in the solid phase. 


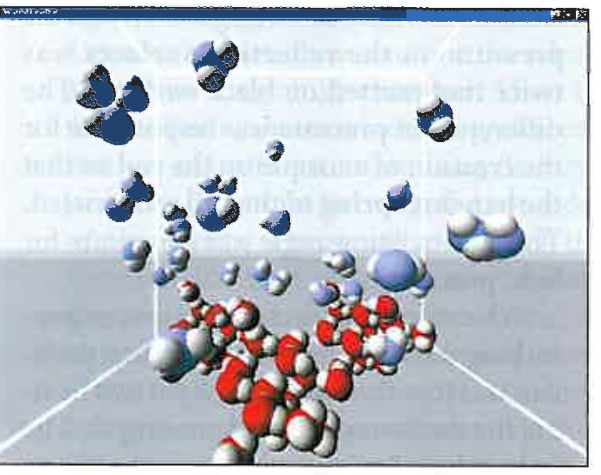

Fig. 3: Snapshot of a virtual reality simulation of water showing the vapour - ice transition. The blue objects make up the gas phase while the red ones are the solid phase (the color is for pedagogical convenience and may be switched off). These pictures were created with "Visual C++" on "WorldToolkit".

most complete sense of immersion. A stereo image gives a stronger sense of depth. The hardware for virtual reality consists of real-time graphics generators, stereo displays or views, tracking sensors, sound machines, and haptic devices. Tracking sensors - which determine the position and orientation of the viewer's head, hands, body parts or other inputs allow the calculation of stereo images, the manipulation of models and the navigation in virtual environments. Sound "machines" provide a sense of location and orientation of certain objects and activities in the environment. Haptic devices vibrate and touch the user's body enhancing the interaction.

Water is an abundant substance but also one with unusual properties. For example, it has a maximum density at $4^{\circ} \mathrm{C}$ in the liquid state and, below $50^{\circ} \mathrm{C}$, the isothermal compressibility grows with cooling (cold water is more "squeezable" than warm water). Moreover, the solid floats on the liquid unlike in other substances.

We are using virtual reality as a tool to introduce students to the molecular bonding and structure of water. Using headmounted colour displays and haptic interfaces, students navigate through an environment created with specialized software ("World Tool Kit"). The environment, under the title "Virtual Water" (http://nautilus.fis.uc.pt/rv), is designed to illustrate scientific concepts such as molecular orbitals and densities, molecular geometry, and the phases and phase transitions of water itself (Fig. 3).

Our molecular dynamics simulations use the equations of Newtonian Mechanics integrated with Verlet's algorithm. We assume classical dynamics because more realistic simulations (incorporating quantum effects) are also much more computationally demanding (SPRIK and PARRINELLO, 2000). We also assume that the force between any pair of molecules depends only on the distance between them, using the Lennard-Jones potential. Some programming tricks were used to obtain a compromise between realistic behaviour and pedagogical utility.

Water molecules in the liquid phase tend to cluster. Computational and laboratorial work has focused on the detailed characterization of the water dimer, trimer, tetramer and large clusters. Some of these isomers are transient structures. The cyclic hexamer (Fig. 4), one of the newest morphologies found in simulations of liquid water, is shown in our virtual environment.

Students exposed to our computer environment were very enthusiastic. One of them wearing a glove said: "I never thought of touching molecules!". Although a quantitative evaluation of the educational impact of our materials is still under way, the virtual environment seems to be a valuable tool. All textbooks and almost all available computer simulations that discuss these concepts stick to $2 \mathrm{D}$ representations, so that the change to a $3 D$ world is quite a dramatic step. The "touch and feel" dimension is an additional stimulating feature.

Problems we faced in implementing our system were the price of hardware / software and the implementation of good graphics and haptics interfaces. A problem in generalizing the use of programs like ours is the "technophobia" of some teachers, which contrasts to the extraordinary computer abilities of some of their students.

\section{Enter the Internet}

Internet is a road to the future. Though the bandwidth in communication channels is not yet satisfactory, the Internet is becoming gradually the preferred vehicle for all those materials. Teaching and learning processes in multimedia formats on the Web have the obvious advantage of making educational content freely available. Molecular simulations in the Web, in a simple and modular format ("Java"), such as those we have described, seem particularly well suited to this new pedagogical genre.

On the other hand, virtual reality offers additional features such as stereo viewing and haptic interaction. The very idea of navigation inside the microscopic world preceded modern computers (see "Mr. Tompkins" book by George Gamow, from

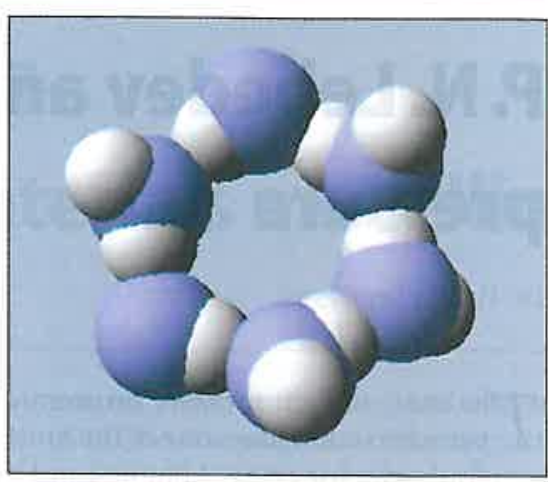

Fig.4: The cyclic water hexamer, which may be regarded as the smallest piece of ice.

which a new edition has appeared (GAMOW and STANNARD, 1999). Our "Virtual Water" project turns this idea "real". We are thinking about a Web version, running either Java or VRML (the Internet 3D language).

Both projects point ways to the future of technology in science education. Computational tools may indeed facilitate the understanding of some scientific concepts. But the complexity of the challenges faced by scientific education does not find a panacea in the new technologies. Many changes are needed, computer technologies being only one of the ways to achieve an improvement.

\section{Acknowledgments}

We are grateful to Dr. Victor Gil and Dr. José Carlos Teixeira for their precious help in these projects.

\section{References}

GAMOW, G. and STANNARD, R. (1999). The New World of Mr. Tompkins, Cambridge University Press.

NAUTA, K. and MILLER, R. E. (2000). Formation of cyclic water hexamer in liquid helium: the smallest piece of ice, Science 14 (287) 293-295.

KALAWSKY, R. (1993). The Science of Virtual Reality and Virtual Environments. Addison-Wesley.

SPRIK, M. and PARRINELLO, M. (2000). Reactive liquids from first principles, $E$ rophysics News, Jul/Aug.

TRINDADE, J., FIOLHAIS, C. and GIL, V. (1999). Virtual Water, an application of virtual environments as an education tool for physics and chemistry. In Advanced Research in Computers and Communication in Education, Proceedings of the 7th International Conference on Computers in Education, Chiba, Japan, ed. G. Cumming et al., vol. 2, IOS Press, 655-658. 
gered the modelling of systems in which there are large concentration gradients and where there may be electronic excitation.

If large national laboratories were crucial to the early stages of materials modelling, the field has developed into an international activity, with a major academic component and a new software industry. There are enormous changes happening in the science, in the computer hardware and software, and in the industries which it might serve. Information technology is changing, and its impact on the ways people work is dramatic. Such changes, coupled with the restructuring of many familiar industries, often at the expense of their R\&D functions, raise questions about the future. We have all seen many changes in the last two decades: changes in computing, notably the rise of the PC; the evolution of software industries; the loss of research from large national laboratories, government or industrial; the reorganisation of industry and the growing international components both in modelling and in the industries to which it relates. It seemed time to assess ways forward. These developments and questions prompted the UK Materials Foresight Panel to seek a review of the issues and the state of UK predictive materials modelling. What did UK scientists think of their roles, their international standing, and of their futures? What should be done? More specifically, to introduce reality into the picture, what might be done without spending any significant money?

There is more to materials modelling than condensed matter physics. There is a drive from technology, which emphasises materials performance and fitness for purpose: photographic materials must function; adhesive joints must adhere. Whole life behaviour is a concern, whether the life of a silicon oxide film under electrical stress or a turbine blade at high temperatures. Customers must accept cost and appearance. There are economic, safety and environmental constraints: polythene bags and aluminium beverage cans may be among the most successful innovations of the twentieth century, but they can create perverse disposal problems. Conventional solid state physicists can concentrate on a far narrower range of systems and situations than those for materials modelling. Baked beans, foam rubber, nuclear fuels and weld materials are all legitimate areas for the materials modeller. The properties can be thermal, mechanical, electrical, magnetic, active optical (like photochromics), catalysts or gas sensors.

The length scales range from the atomic to the macroscopic (engineering) dimensions, with a key mesoscopic regime for which microstructure matters. Timescales can range from femtoseconds to the geological.

It is only natural that the aims of materials modelling differ from those of condensed matter physics. The general thrust is clearly somehow to aid the improvement of materials for identifiable needs. Whether this means new materials, new processes, new inspection methods, or some other development, depends on the context, the constraints and the drivers. The style and level of modelling depends strongly on the problem. The science varies from simple scoping calculations, through systematic use of interatomic potentials and thermodynamic databases to the state-of-the-art electronic structure calculations (often, usually wrongly, called "a priori" or "first principles"). But modelling doesn't depend only

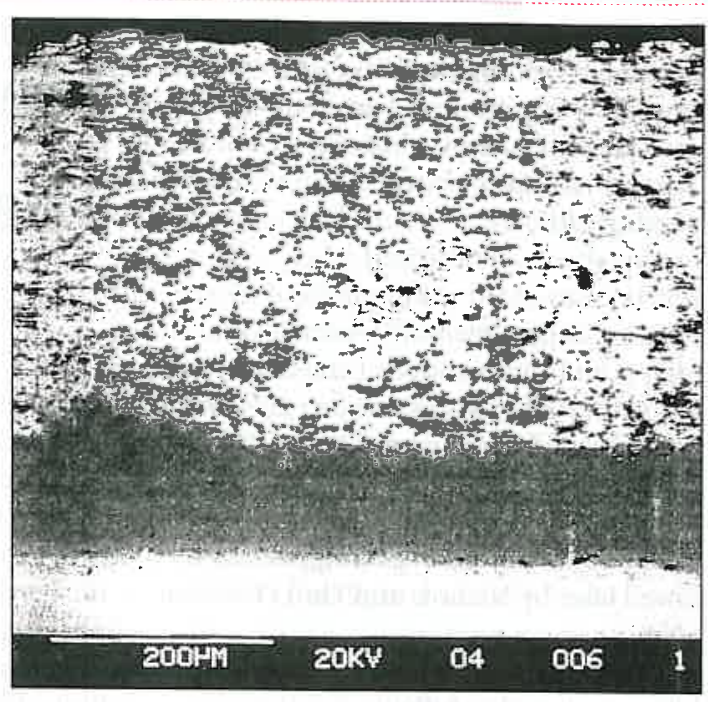

Microstructures of ceramic thermal barrier layers formed by plasma spray deposition, in which small ceramic particles pass through a plasma, where they melt, and then "splat" onto a surface. The model (by I S Doltsinis, J H Harding, M Marchese 1998 Arch Comp Meth in Eng 5 59) modelled all the stages of these processes, including the themal and mechanical properties of the product film; they also developed genetic algorithm tools to optimise operating conditions for chosen properties. on the science: there are constraints from the time and funds available, and from the view as to what is a solution. This is an important difference. Looking at previous reviews of materials modelling, there is an implicit assumption that computer hardware or software is the most serious limitation. This view is changing. The hardest parts now seem to concern brainware and experience. Can you frame the problem in a way which can be modelled at an appropriate level of detail? Can you understand the modelling output well enough to give adequate answers? Have you enough confidence in those answers to take an unpopular decision: could you tell an enthusiastic senior manager "You can't do things this way," for example? Robust reliability is the key to acceptance of modelling.

The response to the UK review carried some surprises. The first surprise was the level of interest. More than half of those sent email questionnaires actually replied. Another substantial group, largely different, came to a meeting in London - it was actually overbooked. One very good feature of Foresight studies is that you meet new, even when you think you know most of the community. The second surprise was the range of subject. We tend to think that our own personal part of the modelling scene is its core, and there isn't much else that we don't know about. As one who has been involved in many fields through working in a large technology-based organisation, I was delighted to realise how much more there was which was unfamiliar to me. The third surprise was that, instead of the hyperconfident tone of some scientific papers, there were serious questions about realism and accuracy. Almost everyone knew that conventional materials modelling (finite element, finite difference, computational fluid dynamics) was allowing manufacturers to avoid building prototypes. The computer has replaced a lot of building of large-scale, real physical models. Yet hardly anyone said "We will design a new material from scratch, such that you can cut out all those tests and experiments." They did not say "We'll design you new aerospace materials by computer, such that we would be happy to fly in a plane built with it." The reality is that present modelling can do an enormous amount to improve materials, or to eliminate tempting but deceptive ideas. Yet its accuracy, even in the hands of the best teams with state-of-the-art codes, is not yet of a quality to eliminate large-scale experimental work. Partly this is because of working approximations; partly because industrial needs are much more complicated than the simpler systems which are 
the usual targets of scientific modelling.

One final surprise was in the nature of the comments. There was not much talk along the lines "Give us bigger computers and we'll sort you out." True, bigger and faster were highly desirable. There was strong support for keeping up with the leaders around the world. But there was far more emphasis on how a human brain can take a technological question and transform it into a scientific question which might (with luck) be answered on a sensible timescale at sensible cost. There was also sympathetic recollection of the saying (originally due to J Willard Gibbs) "Thermodynamics owes more to the steam engine than the steam engine owes to thermodynamics". In other words, novel applied science pushes the scientist towards new basic scientific ideas.

The survey led to a number of recommendations, described below. Even though the emphasis was on the UK, the strongly international character of both science and industry give modelling a broader dimension. There are plenty of opportunities for Europe, although even a European view may be too narrow.

Expansion of materials modelling courses, especially so as to include those scientists with industrial experience. Education is not just for new graduates. Since industry is highly international, the UK should encourage students from all national backgrounds, without restrictive grant rules. Software use (how to run this or that large code) is only a small part of what should be taught. Much more important are "defining the problem" issues, the "brainware" aspects, so that students can address the unanticipated problems in the industries of today and tomorrow. Trained students would be valuable in many roles in industry: student numbers should not be restricted by estimates of numbers anticipated for those doing solely materials modelling.

Experience and learning from the past The losses of know-how and of knowledge are serious, given industrial reorganisation, the closures of large laboratories, the reductions or elimination of their libraries, and the associated losses of unpublished reports. Web searches do not access some important knowledge readily, especially internal reports (and changes of data storage formats may destroy databases which are not transferred; some, especially in declining industries, may be irreplaceable). Effective artificial intelligence approaches need encouragement. There has been a general feeling in some UK circles that networking replaces large labora- tories, and that someone else will do the work and pay the bill. This is not credible. National laboratories should be supported as a national resource for some of these needs, especially when the time scales are longer than those for major reorganisations of industry.

Software industries (which did not exist in the early days of modelling) have a crucial role in transforming early versions of science-based codes from industry or academia into products for non-specialist users. This process is just as hard as turning a prototype of scientific equipment into a laboratory tool. Yet funding the development of software (or hardware) is very difficult in the UK. This must be resolved for the scientific software industries to flourish, ideally allowing development in whichever sector (industry, academia, national laboratory) is best equipped.

Software needs seemed more subtle, since much of the field is less mature. Credibility of results is a very significant issue, often not appreciated sufficiently by scientists. The practical man in industry knows how much to trust Finite Element predictions, but is (rightly) far less sure about electronic structure or mesostructure, where the working assumptions are less instinctive. Even minor academic squabbles about details can damage credibility. Benchmarking may help in some cases; in other areas, easily-accessed, objective advice is needed.

International competition drives enhancement of hardware. It is important that public-funded, state-of-the-art, equipment is available to industry users (as well as to academics) under reasonable conditions.

Management Few managers in industry recognise the opportunities created by predictive modelling. Active groups in industry are often too small and too transient to be effective. Achievements of modelling are easily underestimated, especially its role of filtering out flawed proposals. There are good case studies (like those listed in my first paragraph), and these should be publicised. Management courses could help to create informed customers for modelling.

Timescales Ways must be found to support activities with longer timescales (say 5 years). Such longer perspectives are most easily met in national laboratory or university settings. Universities have particular problems if graduate students write software, since it is hard for them to document it properly on the standard UK timescales.

Materials modelling is itself a wealth-

\section{What is Foresight?}

Foresight is about being ready for the future. No-one can predict the future. What we can do is look ahead and think about what might happen so that we can begin to prepare for it today.

Led by Government, the UK Foresight programme brings together business, the public sector, the science base and others to identify the threats and opportunities that we are likely to face over the next 10 . 20 years. In doing so, Foresight aims to improve wealth creation, enhance quality of life and bring about a culture change in the way business and the science base relate to each other and to the future.

For more information, visit: www.foresight.gov.uk

generating industry. It is relatively new, firmly based in physics and in information technologies. Moreover, it is international, and can gain enormously from collaborations within a framework which generates trust.

My wrist watch contains many new materials new since I was an undergraduate. Even if few, if any, were computer-designed, computer methods would have been conspicuous in their development. The next time you use a mobile phone, drink from an aluminium beverage can, or even eat a new-style ice cream, you'll be dealing with materials which are either new or significantly improved since you were born. And predictive materials modelling made its contribution.

The group which carried out the study for the Office of Science and Technology of the Department of Trade and Industry, was chaired by Marshall Stoneham (Massey Professor and Director of the Centre for Materials Research, University College London, and previously Chief Scientist, AEA Technology), Andy Howe (Principal Scientist, Corus) and Tim Chart (Chart Associates), with the support of John Patterson (BNFL) from the Materials Foresight Panel. We had input from all sectors of the UK community, plus international input, including that from the US Westmoreland Report and from European materials scientists. Our full report will be available on the DTI Foresight Website.

The views in this article are those of Marshall Stoneham. 